\section{Response of Potted Peach Trees to Pruning and Grass Competition}

\author{
Thomas Tworkoski \\ Appalachian Fruit Research Station, U.S. Department of Agriculture, \\ Agriculture Research Service, Kearneysville, WV 25430
}

Additional index words. Prunus persica, fescue, ryegrass, Lolium perenne, Festuca arundinacea, abscisic acid, water status

\begin{abstract}
Peach [(Prunus persica (L.) Batsch., 'Rutgers Redleaf'] trees were grown for two seasons in a greenhouse with three pruning treatments (none, shoot tips removed, and half the shoots removed) and three grass treatments (no grass competition; perennial ryegrass, Lolium perenne L., 'Linn'; and tall fescue, Festuca arundinacea Schreb, 'Kentucky 31'). Competing grass reduced shoot growth, leaf area, and weight of fine roots in shallow soil, but did not affect the growth response to pruning. Regrowth from pruned trees was such that the shoot : root ratio was restored to that of unpruned trees. Leaf water potential, stomatal conductance, and photosynthesis had decreased markedly by 48 hours after irrigation ceased in trees without competition (larger trees) and to a similar level by 96 hours in trees with competition (smaller trees). Apparently, the reduced leaf area of peach trees grown with grass competition delayed water stress. Leaf abscisic acid levels were not directly affected by grass competition but increased as leaf water potential decreased. Grass competition modified morphology and reduced tree size, but did not affect shoot growth following pruning.
\end{abstract}

Managing vegetative and reproductive growth and controlling tree size are priorities for sustainable, productive peach orchards. Tree size can be maintained by pruning aboveground shoots, but new shoots can grow vigorously from buds that were correlatively inhibited before pruning. Annual pruning is a significant expense, and the numerous cuts may provide entry for disease (Hayden and Emerson, 1975).

Peach tree size can be restricted by competition with tall-fescue, and pruning weights per tree can be reduced by continuous competition with grass after planting (Glenn and Welker, 1996). Installing annual ryegrass (Lolium multiflorum Lam.) reduced pruning weights of 5-year-old peach trees in only 1 of 3 years (Huslig et al., 1993). These reports suggest that grass competition can reduce peach tree size, but the effects of grass competition on shoot growth is less clear and may vary with soil resource availability.

Grass competition can alter root growth and reduce nutrient and water uptake in apple (Malus $\times$ domestica Borkh.) trees (Atkinson and White, 1976, 1980). Root growth also can be retarded when shoots of fruit trees grow vigorously following pruning (Atkinson, 1980). Consequently, pruning and grass competition may affect fruit-tree root growth and the capacity to avoid water stress. Water stress can induce biochemical and physiological responses such as accumulation of abscisic acid (ABA) in leaves that in turn


for publication $15 \mathrm{Apr}$. 2000. The cost of publishing this paper was defrayed in part by the payment of page charges. Under postal regulations, this paper therefore must be hereby marked advertisement solely to indicate this fact. reduce stomatal conductance and photosynthesis (Popova et al., 1996). In addition to competition, allelopathic chemicals from certain grasses may inhibit growth of nearby plants. Living plants or decaying residues of perennial ryegrass release inhibitory compounds (Hanwen et al., 1996). Thus, grasses may interfere with fruit-tree growth through a number of mechanisms.

The objectives of these experiments were to demonstrate the effects of pruning and grass competition on growth and response to water stress in greenhouse-grown peach trees. Specific objectives were to determine: 1 ) if grasses interfered with peach tree growth; 2) if tall fescue affected peach tree growth differently ence was greater in heavily pruned trees, which presumably had less photosynthate to support the roots; and 4) the response of peach trees to grass competition and water stress.

\section{Materials and Methods}

Plant materials. In May 1995, one peach seed was planted in each of 54 plastic pots ( 20 $\mathrm{cm}$ diameter and $60 \mathrm{~cm}$ deep) containing Hagerstown silt loam. Natural sunlight was supplemented, and photoperiod was maintained at $16 \mathrm{~h}$ with high-pressure sodium lights $\left(580 \mu \mathrm{mol} \cdot \mathrm{m}^{-2} \cdot \mathrm{s}^{-1}\right.$ photosynthetically active radiation; $23 \pm 5^{\circ} \mathrm{C}$ ). Fifty-four trees were grown in a greenhouse for 8 months, and then grass was planted in selected pots. Trees in the greenhouse were watered daily throughout the experiment and fertilized weekly with $100 \mathrm{~mL}$ of a solution of $20 \mathrm{~N}-$ 8.8P-16.6K $\left(5 \mathrm{~g} \cdot \mathrm{L}^{-1}\right)$ in June 1996. The design of the experiment was a two-way factorial in a randomized complete-block design with three levels of pruning (none, light, and from perennial ryegrass; 3) if grass interfer- heavy) and three levels of competition (none, ryegrass, and fescue), with six replications. Pearson correlation analysis was performed among selected variables.

Perennial ryegrass seeds were sown in the soil beneath the peach tree in 18 pots and tall fescue seeds were sown in 18 additional pots. Eighteen pots contained trees without grass. Within a month, the stand of grass was uniform. At this time, leaves were stripped from the trees, and they were placed in $5^{\circ} \mathrm{C}$ storage in Feb. 1996.

Trees were removed from cold storage after 6 weeks, pruned, and placed back in the greenhouse. Three pruning treatments were used: 1) $0 \%$ (none); 2) <10\% (light); or 3) $\approx 50 \%$ (heavy) of the 1995 shoot length was removed. Five $\mathrm{cm}$ of each terminal was removed from all shoots in the light pruning $(\approx 50 \mathrm{~cm}$ per tree) and about half of each terminal from all shoots in the heavy pruning $(\approx 217 \mathrm{~cm}$ per tree). Trees were grown for 8 months and then placed at $5^{\circ} \mathrm{C}$ for 12 weeks. Trees were removed from cold storage in Feb. 1997 and pruned with the same intensity (none, light, and heavy) that they had received in Feb. 1996. Trees were harvested after 3 months of the second growing season when growth had slowed, and after the conclusion of the waterstress experiment. Pearson correlation analysis was performed among selected variables.

Growth. Shoot growth was measured after the first and second seasons that trees grew with grass (1996 and 1997). Lengths of shoots from previous seasons that remained after pruning also were measured. At the end of the experiment, in Apr. 1997, the whole shoot and root systems of trees and grass were washed, separated according to size or age, and weights, lengths, or areas were measured. Peach stems were cut $1 \mathrm{~cm}$ above the root collar and xylem tissue diameter was measured as the average of perpendicular measurements of the trunk, excluding the green phloem and bark.

Photosynthesis, transpiration, leaf abscisic acid, and water potential. One month after trees were removed from cold storage in 1997, water was withheld. Measurements were taken each day, beginning with the day that the pots were watered to field capacity and ending when photosynthesis stopped and leaves were wilted $(\approx 5 \mathrm{~d})$.

Photosynthesis, transpiration, and stomatal conductance were measured on three mature leaves from different branches on each tree each day (CIRAS-1; PP Systems, Haverhill, Mass.). Immediately after photosynthesis measurement, the leaf was covered and cut, and water potential was measured with a pressure chamber (Soil Moisture Equipment Corp., Santa Barbara, Calif.). The three leaves were then pooled, quickly frozen in liquid $\mathrm{N}$, and lyophilized overnight for abscisic acid (ABA) analysis. The dried leaf was ground with a mortar and pestle, and $0.25 \mathrm{~g}$ was extracted with $80 \%$ methanol, purified with C-18 columns (Sep-Pak; Waters, Milford, Mass.), and quantified with immunoassay (IDEXX Corp., Sunnyvale, Calif.). ${ }^{3} \mathrm{H}-\mathrm{ABA}$ was used as an internal standard. 


\section{Results and Discussion}

Grass competition reduced peach shoot and root dry weight but did not alter the shoot : root dry-weight ratio (S/R) (Table 1). Fescue and ryegrass reduced shoot and root weights similarly. Generally, pruning did not reduce dry weights or S/R. Following heavy or light pruning, regrowth of shoots occurred until a $S / R$ similar to nonpruned trees was achieved. Heavily pruned trees had about twice the new shoot growth of nonpruned trees. No interaction occurred between competition and pruning in terms of shoot growth (Table 2). Grass competition effectively reduced the size of trees, but the relative effects of competition were similar regardless of the level of pruning. Thus, regrowth following pruning appeared to be determined by the severity of pruning and tree size rather than by grass competition.

Total root weight of trees was reduced by grass competition, but only roots in the $0-30$ cm depth were affected (Tables 1 and 3 ). Roots $<1 \mathrm{~mm}$ in diameter were reduced by more than $40 \%$ by fescue and ryegrass. Below the $30-\mathrm{cm}$ soil depth, grass root weight decreased, and peach root weight was not affected by grass competition (Table 3 ). Nearly all components of shoot growth, including leaf number, weight, and area and stem weight were reduced by grass competition (Table 2 and data not shown). Thus, grass appeared to interfere with fine root development of peach trees at shallow depths. This may have resulted in reduced water and nutrient capture and reduced shoot growth.

Correlation analysis supported results from analysis of variance. Peach shoot and root dry weights were negatively correlated with grass shoot dry weight $\left(r=-0.85^{* *}\right.$ and $-0.58^{* *}$, respectively) and with grass root dry weight ( $r$ $=-0.74^{* *}$ and $-0.59^{* *}$, respectively). Only weights of peach roots $<1 \mathrm{~mm}$ in diameter in the $0-30 \mathrm{~cm}$ soil depth were correlated with grass root dry weight $\left(r=-0.48^{* *}\right)$.

When irrigation ceased, increases in leaf ABA lagged behind decreases in leaf water potential and stomatal conductance (Figs. 1 and 2). For example, leaf water potential and

Table 1. Effects of pruning intensity and competition with grasses on dry weight ( $\mathrm{g}$ ) of peach shoots, roots, and shoot : root ratios (S/R).

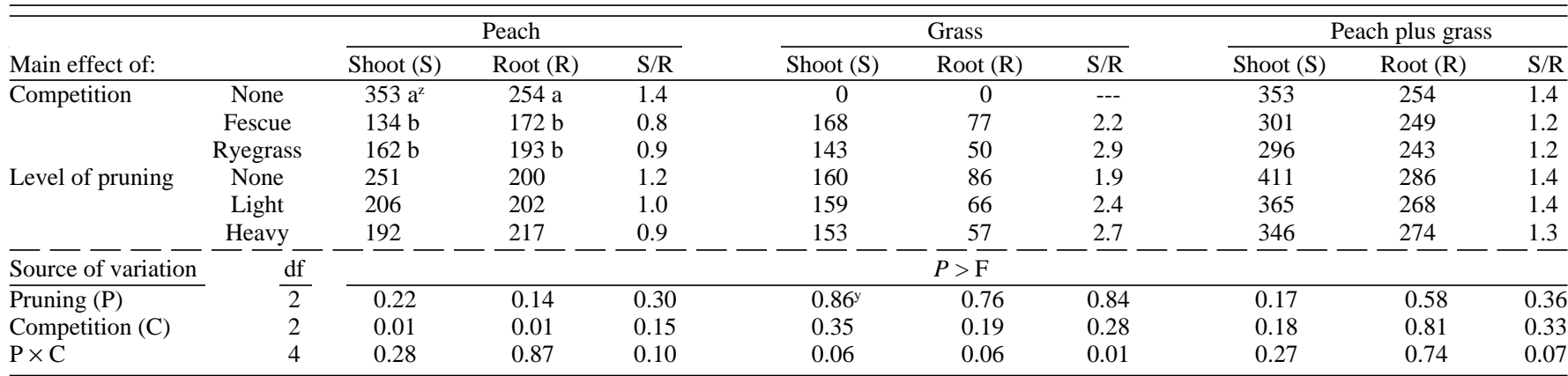

${ }^{2}$ Mean separation within columns and main effects by Ryan-Einot-Gabriel-Welsh multiple range test $(P \leq 0.05)$.

yZero values of no competition were excluded from the ANOVA of grass shoot, root, and S/R.

Table 2. Effects of pruning intensity and competition with grasses on morphological traits of potted peach trees. ${ }^{2}$

\begin{tabular}{|c|c|c|c|c|c|c|c|c|}
\hline \multirow[b]{2}{*}{ Main effect of: } & & \multicolumn{2}{|c|}{ Annual shoot growth $(\mathrm{cm})$} & \multirow{2}{*}{$\frac{\text { Trunk }}{\text { diam }(\mathrm{mm})}$} & \multirow{2}{*}{$\frac{\text { Total leaf }}{\text { area }\left(\mathrm{m}^{2}\right)}$} & \multirow{2}{*}{$\frac{\text { Specific leaf area }}{\left(\mathrm{cm}^{2} \cdot \mathrm{g}^{-1}\right)}$} & \multirow{2}{*}{$\frac{\text { Avg leaf }}{\text { area }\left(\mathrm{cm}^{2}\right)}$} & \multirow{2}{*}{$\frac{\text { Ratio of leaf area to }}{\text { xylem diam }\left(\mathrm{cm}^{2} \cdot \mathrm{mm}^{-1}\right)}$} \\
\hline & & 1996 & 1997 & & & & & \\
\hline Competition & Fescue & $184 \mathrm{~b}$ & $158 \mathrm{~b}$ & $15 \mathrm{~b}$ & $0.39 \mathrm{c}$ & $150 \mathrm{a}$ & $7.2 \mathrm{~b}$ & $305 c$ \\
\hline \multirow[t]{3}{*}{ Level of Pruning } & None & $146 \mathrm{~b}$ & $198 \mathrm{~b}$ & $17 \mathrm{a}$ & $0.74 \mathrm{a}$ & $146 \mathrm{a}$ & $8.3 \mathrm{a}$ & $483 \mathrm{a}$ \\
\hline & Light & $183 \mathrm{~b}$ & $274 a b$ & $17 \mathrm{a}$ & $0.76 \mathrm{a}$ & $150 \mathrm{a}$ & $8.8 \mathrm{a}$ & $516 \mathrm{a}$ \\
\hline & Heavy & $319 \mathrm{a}$ & $359 \mathrm{a}$ & $15 \mathrm{a}$ & $0.87 \mathrm{a}$ & $158 \mathrm{a}$ & $10.4 \mathrm{a}$ & $566 \mathrm{a}$ \\
\hline Source of variation & & & & & $\overline{P>\mathrm{F}}$ & & & \\
\hline $\mathrm{P} \times \mathrm{C}$ & & 0.61 & 0.69 & 0.38 & 0.65 & 0.72 & 0.54 & 0.81 \\
\hline
\end{tabular}

${ }^{2}$ Mean separation within columns and main effects by Ryan-Einot-Gabriel-Welsch multiple range test $(P \leq 0.05)$.

'Total leaf area divided by total leaf weight per tree.

Table 3. Effects of pruning intensity and competition with grasses on belowground weight (g) distribution of potted peach trees at two soil depths and of competing grass. ${ }^{2}$

\begin{tabular}{|c|c|c|c|c|c|c|c|c|c|c|}
\hline \multirow[b]{3}{*}{ Main effect of: } & & \multicolumn{5}{|c|}{ Peach } & \multicolumn{4}{|c|}{ Grass } \\
\hline & & \multicolumn{3}{|c|}{$\begin{array}{l}0 \text { to } 30 \mathrm{~cm} \text { depth } \\
\text { Root diam }(\mathrm{mm})\end{array}$} & \multicolumn{2}{|c|}{$\begin{array}{l}30 \text { to } 60 \mathrm{~cm} \mathrm{depth} \\
\text { Root diam }(\mathrm{mm})^{\mathrm{y}}\end{array}$} & \multirow[b]{2}{*}{ Leaves } & \multirow[b]{2}{*}{ Crown } & \multicolumn{2}{|c|}{$\begin{array}{l}\text { Root depth } \\
\quad(\mathrm{cm})\end{array}$} \\
\hline & & $<1$ & 1 to 5 & $>5$ & $<1$ & 1 to 5 & & & 0 to 30 & 30 to 60 \\
\hline \multirow{4}{*}{ Level of Pruning } & Fescue & $14 \mathrm{~b}$ & $25 \mathrm{~b}$ & $84 \mathrm{~b}$ & $46 \mathrm{a}$ & $18 \mathrm{a}$ & $70 \mathrm{a}$ & $98 \mathrm{a}$ & $69 \mathrm{a}$ & $8 \mathrm{a}$ \\
\hline & Ryegrass & $17 \mathrm{~b}$ & $29 \mathrm{~b}$ & $91 \mathrm{ab}$ & $42 \mathrm{a}$ & $15 \mathrm{a}$ & $44 \mathrm{~b}$ & $100 \mathrm{a}$ & $48 \mathrm{~b}$ & $4 \mathrm{~b}$ \\
\hline & None & $25 \mathrm{a}$ & $33 \mathrm{a}$ & $92 \mathrm{a}$ & $36 \mathrm{a}$ & 0 & $40 \mathrm{a}$ & $61 \mathrm{a}$ & $51 \mathrm{a}$ & $5 \mathrm{a}$ \\
\hline & Light & $17 \mathrm{a}$ & $32 \mathrm{a}$ & $90 \mathrm{a}$ & $44 \mathrm{a}$ & $18 \mathrm{a}$ & $40 \mathrm{a}$ & $67 \mathrm{a}$ & $40 \mathrm{a}$ & $4 \mathrm{a}$ \\
\hline Source of variation & df & \multicolumn{9}{|c|}{$P>\mathrm{F}$} \\
\hline Pruning $(\mathrm{P})$ & 2 & 0.44 & 0.93 & 0.51 & 0.61 & 0.52 & 0.58 & 0.92 & 0.38 & 0.12 \\
\hline Competition (C) & 2 & 0.04 & 0.09 & 0.15 & 0.60 & 0.77 & 0.01 & 0.01 & 0.01 & 0.01 \\
\hline $\mathrm{P} \times \mathrm{C}$ & 4 & 0.09 & 0.08 & 0.36 & 0.17 & 0.33 & 0.32 & 0.31 & 0.11 & 0.92 \\
\hline
\end{tabular}

${ }^{2}$ Means separation within columns and main effects by Ryan-Einot-Gabriel-Welsch multiple range test $(P \leq 0.05)$.

${ }^{y}$ Roots with diameters $>5 \mathrm{~mm}$ were not found at the 30 - to $60-\mathrm{cm}$ depth. 
stomatal conductance of trees without competition decreased markedly between 24 and 48 $\mathrm{h}$, but leaf ABA did not markedly increase until 48 to $72 \mathrm{~h}$. Leaf ABA was correlated with transpiration $\left(r=-0.18^{* *}\right)$ but not with leaf water potential ( $r=-0.10$; nonsignificant at $P$ $\leq 0.05)$. Transpiration was correlated with leaf water potential $\left(r=-0.72^{* *}\right)$. While increases in xylem-derived ABA may occur because of drought stress (Davies and Zhang, 1991), the large increase of ABA in leaves in this experiment was not an early event in peach-tree response to water stress. However, the small increase in ABA from 24 to $48 \mathrm{~h}$ may have been physiologically significant.

Correia et al. (1997) found that peach leaf stomates opened in the morning despite high xylem ABA, and stomate responsiveness to $\mathrm{ABA}$ increased during the day. In the current experiment, measurements were taken close to 10:00 AM and stomate sensitivity to ABA may have increased later. After irrigation ceased, leaf water potential and ABA were affected by competition but not by pruning. Trees grown without competition had greater leaf area and leaf-area : xylem-diameter ratio, which may have caused greater water use and stress compared with smaller trees growing with competition (Table 2).

Competition for water very likely occurred between grass and peach trees. Peach leaf water potential $72 \mathrm{~h}$ after cessation of irrigation was more negative as grass crown and root dry weight increased (data not shown). However, peach trees appeared to be better competitors for water than grass or to avoid water stress. Even though grass moisture status was not measured, grass leaves wilted before peach leaves. Thus, the combination of a smaller tree size and greater capacity to exploit soil water, possibly from deeper soil layers, may have delayed water stress in peach trees grown with grass competition.

Trees grown without competition were larger than those grown with competition, and stomatal conductance and photosynthesis of the larger trees declined earlier and at a faster rate after irrigation ceased (Table 1, Fig. 2). However, the total root and shoot weight per pot of grass plus peach tree was uniform for all treatments (Table 1). Soil moisture depletion was fastest with trees grown without competition (Fig. $1 \mathrm{C}$ ). Trees grown with grass competition from either species had less root weight (Table 1), particularly roots $<1 \mathrm{~mm}$ in diameter at the $0-30 \mathrm{~cm}$ depth where grass roots were abundant (Table 3).

Total leaf area and the ratio of leaf area to xylem diameter were less in trees grown with competition than in those grown without competition (Table 2), and total water demand was probably less in trees grown with grass. Peach trees grown with fescue had less leaf area than those grown with ryegrass (Table 2). This may be associated with greater fescue weight (Table 3). Correlation coefficients between ground cover total dry weight and peach leaf area, xylem diameter, trunk diameter, 1997 stem dry weight, and root dry weight at the 0 to $30 \mathrm{~cm}$ depth were -0.84 , $-0.67,-0.48,-0.72$, and -0.63 , respectively
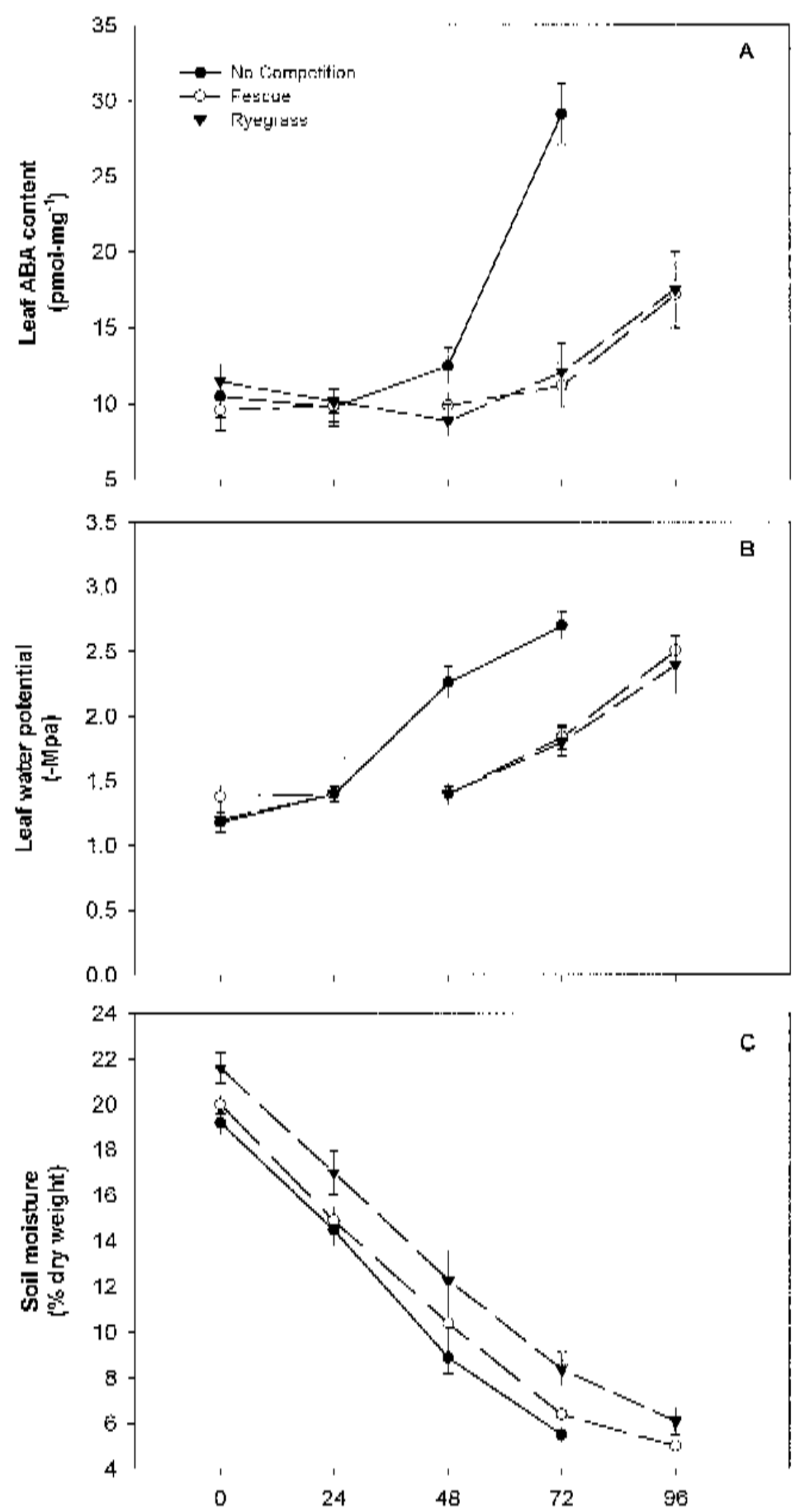

Time without water (h)

Fig. 1. (A) Leaf abscisic acid concentration, (B) leaf water potential, (C) and soil moisture changes following cessation of watering peach trees in the greenhouse. The effects of pruning were nonsignificant and competition treatments were averaged across pruning treatments. Bars represent one $\pm \mathrm{SE}$. 



Fig. 2. (A) Photosynthesis and (B) stomatal conductance changes following cessation of watering peach trees in the greenhouse. The effects of pruning were nonsignificant, and competition treatments were averaged across pruning treatments. Bars represent one $\pm \mathrm{SE}$.

$(P \leq 0.01)$. Previous research suggested that grass may reduce peach tree size by competing for resources (Glenn et al., 1996; Tworkoski et al., 1997). The current experiment indicates that peach trees grown with grass competition may be less susceptible to drought stress because of reduced size, a greater percentage of peach tree root weight below grass roots, and lower leaf-area : xylem-diameter ratio. This altered morphology may have been caused by competition for space, water, or mineral nutrients.

A practical implication of the current work is that shoot regrowth following pruning was determined by the amount of pruning and by crease at a faster rate in trees grown with competition than in those without competition. These findings are based on a model system that increased the chances for competitive interaction between the tree and the grass. In the field, competition may be reduced by spacial avoidance between tree and grass roots. Trees grown with grass competition must be evaluated to determine whether or not similar morphological modifications occur under field soil conditions. The results suggest that grass competition will effectively control young peach tree size and that the differential reduction in shoot regrowth caused by competition was similar across all pruning treatments.

\section{Literature Cited}

Atkinson, D. 1980. The distribution and effectiveness of the roots of tree crops. Hort. Rev. 2:424 490.

Atkinson, D. and G.C. White. 1976. The effect of the herbicide strip system of management on root growth of young apple trees and the soil zones from which they take up mineral nutrients. Rpt. East Malling Res. Sta. for 1975:165-167.

Atkinson, D. and G.C. White. 1980. Some effects of orchard soil management on the mineral nutrition of apple trees, p. 241-254. In: D. Atkinson, J.E. Jackson, R.O. Sharples, and W.M. Waller (eds.). The mineral nutrition of fruit trees. Butterworths, Borough Green, U.K.

Correia, M.J., M.L. Rodrigues, M.I. Ferreira, and J.S. Pereira. 1997. Diurnal change in the relationship between stomatal conductance and abscisic acid in the xylem sap of field-grown peach trees. J. Expt. Bot. 48:1727-1736.

Davies, W.J. and J. Zhang. 1991. Root signals and the regulation of growth and development of plants in drying soil. Annu. Rev. Plant Physiol. Mol. Biol. 42:55-76.

Glenn, D.M. and W.V. Welker. 1996. Sod competition in peach production: I. Managing sod proximity. J. Amer. Soc. Hort. Sci. 121:666-669.

Glenn, D.M., W.V. Welker, and G.M. Greene. 1996. Sod competition in peach production. II. Establishment beneath mature trees. J. Amer. Soc. Hort. Sci. 121:670-675.

Hanwen, W., H. Naber, and G. Oomen. 1996. The allelopathic effect of dead and living mulches from English ryegrass (Lolium perenne L.) on Calystegia sepium (L.). Proc. First World Cong. on Allelopathy, Cadiz, Spain. p. 251.

Hayden, R.A. and F.H. Emerson. 1975. Summer pruning the peach, p. 263-269. In: N.F. Childers (ed.). The peach. Hort. Publications, New Brunswick, N.J.

Huslig, S.M., M.W. Smith, and G.H. Brusewitz. 1993. Irrigation schedules and annual ryegrass as a ground cover to conserve water and control peach tree growth. HortScience 28:908-913.

Popova, L.P., T.D. Tsonev, G.N. Lazova, and Z.G. Stoinova. 1996. Drought- and ABA-induced changes in photosynthesis of barley plants. Physiol. Plant. 96:623-629.

Tworkoski, T.J., D.M. Glenn, and W.V. Welker. 1997. Carbohydrate and nitrogen partitioning within one-year shoots of young peach trees grown with grass competition. HortScience 32:1174-1177. 